\title{
Quality of life of COVID-19 critically ill survivors after ICU discharge: 90 days follow-up
}

\author{
Lorenzo Gamberini ${ }^{1}$ - Carlo Alberto Mazzoli ${ }^{1} \cdot$ Harri Sintonen $^{2}$ - Davide Colombo ${ }^{3,4}$. Gaetano Scaramuzzo ${ }^{5}$. \\ Davide Allegri ${ }^{6} \cdot$ Tommaso Tonetti $^{7}$. Gianluca Zani ${ }^{8}$. Chiara Capozzi ${ }^{9} \cdot$ Emanuela Giampalma $^{10} \cdot$ Vanni Agnoletti $^{11}$. \\ Filippo Becherucci ${ }^{12}$. Elisabetta Bertellini $i^{13,21}$. Andrea Castelli ${ }^{9}$. lacopo Cappellini ${ }^{12}$. Irene Cavalli ${ }^{7}$. \\ Federico Crimaldi ${ }^{13,21}$. Federica Damiani ${ }^{14}$ - Maurizio Fusari ${ }^{8}$. Giovanni Gordini ${ }^{1}$. Cristiana Laici ${ }^{15}$. \\ Maria Concetta Lanza ${ }^{16} \cdot$ Mirco Leo $^{17}$. Andrea Marudi ${ }^{13,21}$. Giuseppe Nardi ${ }^{18}$. Irene Ottaviani ${ }^{5} \cdot$ Raffaella Papa $^{19}$. \\ Antonella Potalivo $^{18}$. Vito Marco Ranieri ${ }^{7}$. Emanuele Russo ${ }^{11}$. Stefania Taddei ${ }^{20}$. Carlo Alberto Volta ${ }^{5}$. \\ Savino Spadaro ${ }^{5}$ - the ICU-RER COVID-19 Collaboration
}

Accepted: 28 April 2021 / Published online: 12 May 2021

(c) The Author(s), under exclusive licence to Springer Nature Switzerland AG 2021

\begin{abstract}
Purpose The onset of the coronavirus disease 19 (COVID-19) pandemic in Italy induced a dramatic increase in the need for intensive care unit (ICU) beds for a large proportion of patients affected by COVID-19-related acute respiratory distress syndrome (ARDS). The aim of the present study was to describe the health-related quality of life (HRQoL) at 90 days after ICU discharge in a cohort of COVID-19 patients undergoing invasive mechanical ventilation and to compare it with an age and sex-matched sample from the general Italian and Finnish populations. Moreover, the possible associations between clinical, demographic, social factors, and HRQoL were investigated.

Methods COVID-19 ARDS survivors from 16 participating ICUs were followed up until 90 days after ICU discharge and the HRQoL was evaluated with the 15D instrument. A parallel cohort of age and sex-matched Italian population from the same geographic areas was interviewed and a third group of matched Finnish population was extracted from the Finnish 2011 National Health survey. A linear regression analysis was performed to evaluate potential associations between the evaluated factors and HRQoL.

Results 205 patients answered to the questionnaire. HRQoL of the COVID-19 ARDS patients was significantly lower than the matched populations in both physical and mental dimensions. Age, sex, number of comorbidities, ARDS class, duration of invasive mechanical ventilation, and occupational status were found to be significant determinants of the 90 days HRQoL. Clinical severity at ICU admission was poorly correlated to HRQoL.

Conclusion COVID-19-related ARDS survivors at 90 days after ICU discharge present a significant reduction both on physical and psychological dimensions of HRQoL measured with the 15D instrument.
\end{abstract}

Trial Registration: NCT04411459.

Keywords COVID-19 Coronavirus · Acute respiratory distress syndrome $\cdot 15 \mathrm{D}$ instrument $\cdot$ Health-related quality of life

$\begin{array}{ll}\text { Abbreviations } \\ \text { ICU } & \text { Intensive Care Unit } \\ \text { IMV } & \text { Invasive Mechanical Ventilation } \\ \text { LOS } & \text { Length of stay } \\ \text { PICS } & \text { Post-intensive care syndrome } \\ \text { IRB } & \text { Institutional Review Board }\end{array}$

Savino Spadaro

savinospadaro@gmail.com

Extended author information available on the last page of the article
HRQoL Health-related quality of life

ICUAW ICU-Acquired Weakness

\section{Introduction}

The coronavirus disease (COVID-19) pandemic in Italy [1] rapidly induced an overburdening situation mostly due to a sudden increase of ICU admission [2-4] for respiratory and multiorgan [5] support. 
COVID-19-related ARDS is an overwhelming disease that can require extended periods of invasive mechanical ventilation [6] and is characterized by a mortality rate that exceeds 50\% in some reports [6-9].

Due to the magnitude of the pandemic, the evaluation of COVID-19 impact on ICU survivors could be useful to identify who may benefit for long-term follow-up and rehabilitation [10].

Several studies have been focused on the identification of tools able to recognize, define, and treat the long-term effects of ICU on quality of life. Post-intensive care syndrome (PICS) [11-13] is characterized by cognitive [14, 15], psychological and physical impairment that can affect ICU survivors [16]. Moreover, ARDS [17, 18], sepsis, delirium [19], and the need for invasive mechanical ventilation (IMV), which are common features in COVID-19 patients [5], are known risk factors for the development of this PICS syndrome.

Some registered ongoing trials aim to define the quality of life after COVID-19 infection (ClinicalTrials.gov NCT04375709, NCT04377464) but these studies do not focus on critically ill patients [20]. Notably, health-related quality of life (HRQoL) [12, 21] in "classical" ARDS survivors is impaired, as showed in previous studies.

The primary aim of the present study was to evaluate the HRQoL at 90 days after ICU discharge in a cohort of critically ill COVID-19 patients who required invasive mechanical ventilation. Furthermore, we compared this population to an age and sex-matched sample of the general Italian and Finnish populations. The comparison with contemporary general Italian population had the objective to specifically assess the potential areas of intervention for the most affected HRQoL dimensions in COVID-19 survivors. On the other hand, in absence of previous Italian studies evaluating general population with the $15 \mathrm{D}$ instrument, a Finnish population sample from the 2011 National Finnish Health Survey data [22] was adopted as a pre-COVID Western-type population for comparison.

The secondary aim was to identify clinical, demographic, social factors than can play a role in the impairment of HRQoL.

\section{Materials and methods}

This prospective multicenter observational study involved 16 Italian ICUs. Patients admitted in the ICU from the 22nd of February to the 4th of May 2020 (the end of lockdown in Italy) were screened for eligibility and followed up until 90 days after ICU discharge. The original study was registered in ClinicalTrials.gov (NCT04411459).

\section{Inclusion, exclusion criteria, and Ethical aspects}

Inclusion criteria were: (a) age $>18$ years; (b) admission to ICU due to respiratory failure determined by SARS-CoV-2 infection confirmed by real-time reverse transcriptionpolymerase chain reaction assays from either nasal swabs or lower respiratory tract sample; (c) need of invasive mechanical ventilation during ICU stay.

Exclusion criteria were: SARS-CoV2 positive patients admitted to the hospital for other reasons (i.e., trauma, stroke) b) refuse to participate to the study.

The study was approved by the Institutional Review Board (IRB) of the study coordinator centre (Maggiore Hospital, Bologna, Italy, approval number: 273/2020/ OSS/AUSLBO) and by each institutional review committee of the participating hospitals. Informed consent was collected during ICU stay and/or follow-up according to the approval of the local Ethics committee. All data were analyzed anonymously.

\section{Data collection}

Data were collected by one investigator from each hospital in an electronic case report form developed by YGHEA, CRO division of Ecol Studio SPA (Bologna Operational Headquarters), and hosted by Actide Nubilaria (Novara, Italy). Demographic data, clinical symptoms or signs at presentation, comorbidities, Sequential Organ Failure Assessment (SOFA) and Score, and Simplified Acute Physiology Score (SAPS) II were collected at ICU admission. All the patients met the Berlin criteria definition for ARDS [23]. The need for renal replacement therapy, need of tracheostomy, duration of invasive mechanical ventilation, prone positioning, use of intravenous corticosteroids, use of a continuous infusion of neuromuscular blocking agents, use of vasoactive drugs, duration of ICU, and hospital stay were also collected and included in the final analysis. Furthermore, the health-related quality of life was assessed using the 15D questionnaire at 90 days from ICU discharge by phone call. Social variables (marital status, occupational status and instruction degree) were collected during follow-up. In case of patients missed at follow-up, we obtained these data from the medical records. Details of the other variables collected are available on clinicaltrials.gov (NCT04411459).

A sex and age-matched random sample from the general Italian population not affected by COVID-19 was interviewed in parallel to create a reference group. Moreover, as described above, in order to create a reference category for the pre-COVID-19 era, and due to the unavailability of Italian HRQoL data measured with the 15D instrument for 
that period, an equally sampled general Finnish population group was obtained from the 2011 National Finnish Health Survey data [22].

\section{The 15D instrument}

The 15D is a widely used, validated, and standardized instrument that explores 15 dimensions (mobility, vision, hearing, breathing, sleeping, eating, speech, excretion, usual activities, mental function, discomfort and symptoms, depression, distress, vitality and sexual activity). Five ordinal levels can be defined for each dimension, by which more or less of the attribute is distinguished. The respondent chooses from each dimension the level which best describes her/his present health status and a score between 1 (lower level) and 5 (upper level) is assigned [24].

The valuation system is based on the multiattribute utility theory. The single index score (15D score) represents the overall HRQoL on a $0-1$ scale ( $1=$ full health, $0=$ being dead). The score of each dimension is calculated from the health state descriptive system using a set of populationbased preference or utility weights. Mean dimension level values are used to draw 15D profiles for groups. Moreover, the minimum clinically important change or difference in the $15 \mathrm{D}$ score has been estimated to be \pm 0.015 on the basis that people can on average feel such a difference [25]. The 15D scores are shown to be highly reliable, sensitive, and responsive to change, there is a considerable degree of agreement between health state evaluations from several European countries and these latter are generalizable at least in Western-type societies [24-26]. Moreover, the 15D instrument has already been applied in follow-up studies of ICU patients [27, 28].

\section{Statistical analysis}

Statistical analysis was performed using IBM SPSS Statistics (IBM Corp. Released 2019. IBM SPSS Statistics for Windows, Version 26.0. Armonk, NY: IBM Corp) and R Core Team 2020 (R: A language and environment for statistical computing. R Foundation for Statistical Computing, Vienna, Austria URL https://www.R-project.org/).

Continuous variables were expressed as means and standard deviations or median and interquartile range (IQR) when appropriate, while categorical variables were expressed as numbers and percentages. Comparisons between continuous variables were performed with Student's t-test or Mann-Whitney U test; categorical variables were compared using Chi-square test. HRQoL values were expressed with the 15D instrument as means and standard deviations and t-test was used for comparisons, regardless from distribution.

Since the 15D value can be calculated only if all the 15 dimensions values are available, missing data on single dimensions of the 15D instrument were estimated using a multiple imputation technique when the missing data involved less than three dimensions [24].

Multiple univariate linear regression analyses were performed on the variables which could be rationally associated to 90-days HRQoL, and a multivariate model was computed using a least angle regression (LAR) selection [29] in order to select significant explanatory terms with respect to survivors' HRQoL.

$P$ values $<0.05$ were considered statistically significant, and all tests were two-sided.

\section{Results}

Over the study period, 632 patients were screened for eligibility. Of these, 162 patients were excluded because they did not undergo invasive mechanical ventilation $(n=120)$ or because of missing data $(n=42)$. The remaining 470 patients were enrolled in the study. Two hundred and eighty-two patients out of $470(60 \%)$ were discharged alive from the ICU and 4 of these died within 90 days after ICU discharge. Therefore, the final follow-up cohort included a total of 278 patients. The flow chart of the patients through the study is shown in Fig. 1. Two hundred five out of 278 patients (73.7\%) responded to the $15 \mathrm{D}$ questionnaire.

The main demographics, comorbidities, and ICU- and hospital-related variables of the patients are shown in Table 1. Overall, patients were predominantly male (74.1\%), the median age was 64.5 years; the most frequent comorbidity was hypertension (51.8\%). The majority of patients experienced a moderate ARDS (55\%), a continuous infusion of neuromuscular blocking agents was used in $89.6 \%$ of cases, prone positioning was performed at least once in $62.9 \%$ of the patients and tracheostomy in $61.5 \%$ of them.

The median length of mechanical ventilation, ICU, and hospital stay were, respectively, 16, 23, and 43 days.

Respondents were younger than non-respondents (63 vs 66 years), had a slightly lower SOFA score at ICU admission and needed less frequently renal replacement therapy; no differences were found for other variables.

Follow-up CT scans were available for 23 out of the 205 respondents and were performed at a median of 61 (35-99) days after ICU discharge (Supplement Table S1). Only two patients $(8.7 \%)$ had a normal follow-up CT scan, while the other presented residual ground glass $(65.2 \%)$, fibrosis (47.8\%), consolidations (30.4\%), pleural effusion (21.7\%), or bronchiectasis (13\%).

Missing data for the 15D instrument, that were replaced by multiple imputation technique, accounted for less than $0.3 \%$ of the cases in most of the dimensions, with exception for usual activities ( $0.5 \%)$, discomfort (1\%), symptoms (1\%), and sexual activity (13.4\%). 
Fig. 1 Patients flow through the study

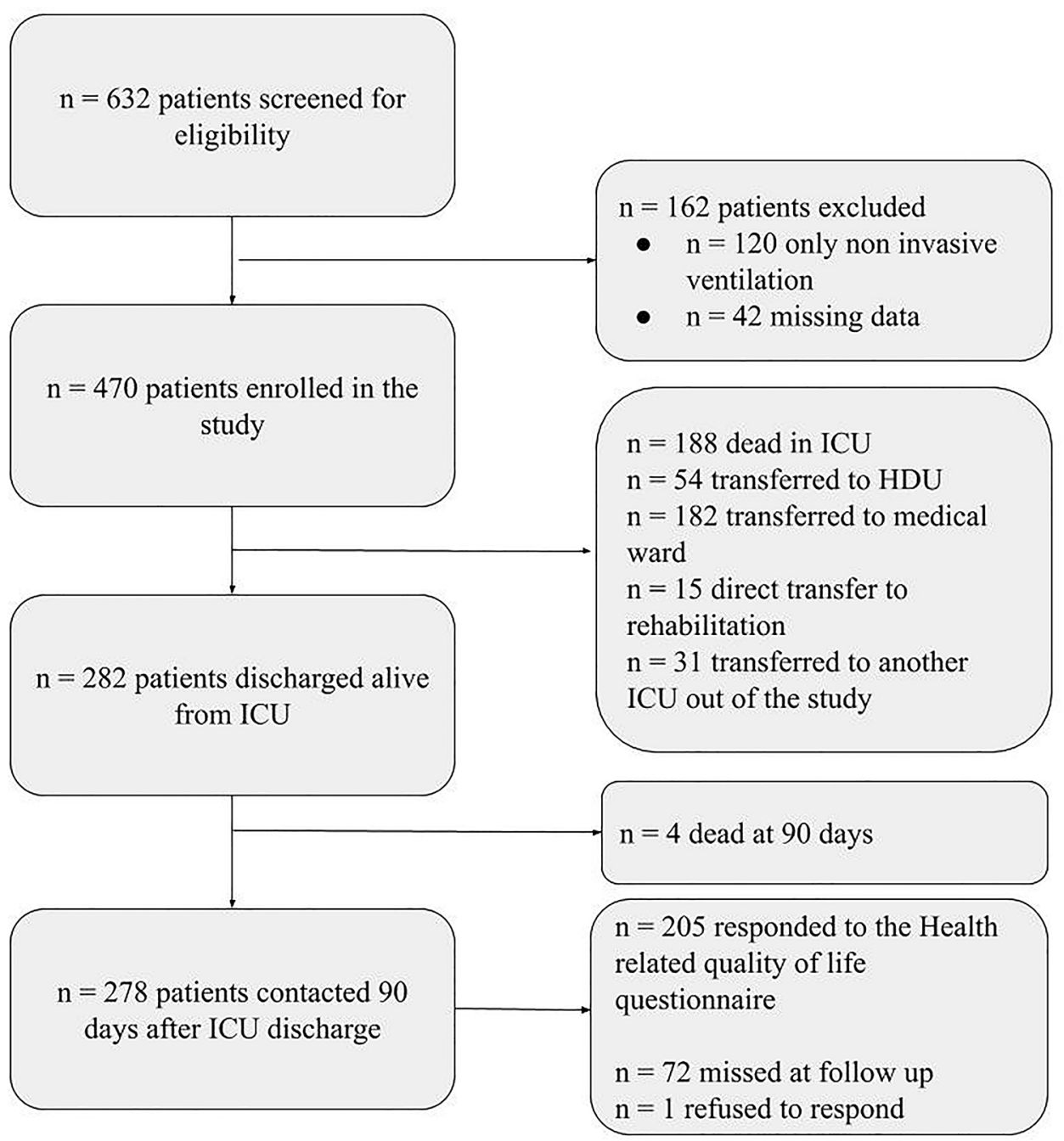

The 15D score of the study population at 90 days after ICU discharge was significantly lower than the two matched controls of Italian and Finnish samples of general population, with a mean value of 0.850 vs 0.928 and 0.914 , respectively. Table 2 shows the mean values for the single dimensions and their comparisons. Figure 2 describes the 15D profiles of the three populations compared.

Considering the single dimensions of the 15D instrument, the mean values for mobility, breathing, eating, speech, usual activities, depression, vitality, and sexual activity were significantly lower when compared both to the matched Italian and Finnish populations, while mental function resulted significantly lower only with respect to Italian population and distress only with respect to the Finnish population (Table 2).

The comparison of the matched samples of general Italian and Finnish populations revealed significant differences on most of the dimensions and on the total 15D score. However, despite the observed difference in the global 15D score was statistically significant, it did not reach the minimum value of \pm 0.015 that is the threshold value that most of the people need to feel such difference [25].

On the basis of univariate linear regression analyses, the variables age, number of comorbidities, ARDS class, SAPS II score, prone positioning, use of vasoactive drugs, duration of invasive mechanical ventilation, ICU length of stay, tracheostomy, need for renal replacement therapy, non-pulmonary complications of ICU stay and occupational status were significantly associated to 90-days HRQoL. The final model obtained after least angle regression selection demonstrated that female sex, increasing age, number of comorbidities, ARDS class, duration of mechanical ventilation, and inability to return to work were significantly associated with a reduction in HRQoL. Table 3 shows the univariate regression analyses and the final multivariate model after the LAR selection of the variables included. The magnitude of potential changes in HRQoL demonstrated by the linear regression analysis is relevant from a clinical point of view because an increase of one comorbidity as well as ARDS class 
Table 1 Characteristics of the patients enrolled in the study

\begin{tabular}{|c|c|c|c|c|}
\hline Demographics & $\begin{array}{l}\text { Total population } \\
n=278\end{array}$ & $\begin{array}{l}\text { Respondents } \\
n=205\end{array}$ & $\begin{array}{l}\text { Non-Respondents } \\
n=73\end{array}$ & $p$ \\
\hline Age-years (IQR) & $64.5(57-70)$ & $63(55-70)$ & $66(61-71)$ & 0.043 \\
\hline Sex-male-no $(\%)$ & $206(74.1 \%)$ & $149(72.7 \%)$ & $57(78.1 \%)$ & 0.366 \\
\hline $\mathrm{BMI}-\mathrm{kg} / \mathrm{m} 2$ (IQR) & $28(26-31)$ & $28(26-31)$ & $28(26-31)$ & 0.608 \\
\hline Comorbidities & $n=278$ & $n=205$ & $n=73$ & $p$ \\
\hline Hypertension-no (\%) & $144(51.8 \%)$ & $102(49.8 \%)$ & $42(57.5 \%)$ & 0.253 \\
\hline Chronic ischemic heart disease-no (\%) & $23(8.3 \%)$ & $14(6.8 \%)$ & $9(12.3 \%)$ & 0.143 \\
\hline Chronic kidney disease (CKD) & $13(4.7 \%)$ & $7(3.4 \%)$ & $6(8.2 \%)$ & 0.110 \\
\hline COPD—no (\%) & $18(6.5 \%)$ & $15(7.3 \%)$ & $3(4.1 \%)$ & 0.418 \\
\hline Diabetes-no $(\%)$ & $48(17.3 \%)$ & $34(16.6 \%)$ & $14(19.2 \%)$ & 0.615 \\
\hline Chronic liver disease (MELD > 10)—no (\%) & $1(0.4 \%)$ & $0(0 \%)$ & $1(1.4 \%)$ & 0.263 \\
\hline Active cancer-no $(\%)$ & $1(0.4 \%)$ & $1(0.5 \%)$ & $0(0 \%)$ & 1.000 \\
\hline \multicolumn{5}{|l|}{ Number of comorbidities-no (\%) } \\
\hline 0 & $111(39.9 \%)$ & $87(42.4 \%)$ & $24(32.9 \%)$ & \multirow[t]{5}{*}{0.297} \\
\hline 1 & $108(38.8 \%)$ & $78(38 \%)$ & $30(41.1 \%)$ & \\
\hline 2 & $43(15.5 \%)$ & $30(14.6 \%)$ & $13(17.8 \%)$ & \\
\hline 3 & $10(3.6 \%)$ & $5(2.4 \%)$ & $5(6.8 \%)$ & \\
\hline 4 & $6(2.2 \%)$ & $5(2.4 \%)$ & $1(1.4 \%)$ & \\
\hline Intensive care and hospital stay & $n=278$ & $n=205$ & $n=73$ & $p$ \\
\hline SAPS II score (IQR) & $35(30-42)$ & $35(29-42)$ & $35(30-43)$ & 0.644 \\
\hline SOFA score at ICU admission (IQR) & $4(3-6)$ & $4(3-6)$ & $4(3-7)$ & 0.044 \\
\hline Intravenous corticosteroids & $183(65.8 \%)$ & $140(68.3 \%)$ & $43(58.9 \%)$ & 0.146 \\
\hline Neuromuscular blocking agents continuous infusion & $249(89.6 \%)$ & $186(90.7 \%)$ & $63(86.3 \%)$ & 0.288 \\
\hline Prone positioning & $175(62.9 \%)$ & $130(63.4 \%)$ & $45(61.6 \%)$ & 0.780 \\
\hline Vasoactive drugs & $171(62 \%)$ & $125(61.3 \%)$ & $46(63.9 \%)$ & 0.694 \\
\hline \multicolumn{5}{|l|}{ ARDS class-no (\%) } \\
\hline Mild (PaO2/FiO2 200-300) & $14(5 \%)$ & $8(3.9 \%)$ & $6(8.2 \%)$ & \multirow[t]{3}{*}{0.234} \\
\hline Moderate $(\mathrm{PaO} 2 / \mathrm{FiO} 2$ 100-200) & $153(55 \%)$ & $111(54.1 \%)$ & $42(57.5 \%)$ & \\
\hline Severe $(\mathrm{PaO} 2 / \mathrm{FiO} 2<100)$ & $111(40 \%)$ & $86(42 \%)$ & $25(34.2 \%)$ & \\
\hline Tracheostomy-no $(\%)$ & $171(61.5 \%)$ & $125(61 \%)$ & $46(63 \%)$ & 0.759 \\
\hline Renal replacement therapy-no (\%) & $29(10.4 \%)$ & $15(7.3 \%)$ & $14(19.2 \%)$ & 0.004 \\
\hline Length of invasive mechanical ventilation-d (IQR) & $16(10-28)$ & $16(10-27)$ & $18(11-35)$ & 0.092 \\
\hline Length of ICU stay-d (IQR) & $23(15-38)$ & $23(15-35)$ & $26(14-46)$ & 0.238 \\
\hline Length of hospital stay $(n=248)^{*}-\mathrm{d}$ (IQR) & $43(30-61)$ & $42(31-57)$ & $55(28-79.5)$ & 0.142 \\
\hline Socioeconomic variables & $n=226^{*}$ & $n=205$ & $n=21^{*}$ & $p$ \\
\hline Marital status—married/cohabitee-no (\%) & $170(75.2 \%)$ & $156(76.4 \%)$ & $14(66.7 \%)$ & 0.340 \\
\hline Instruction degree- - high school or higher-no (\%) & $147(65.0 \%)$ & $130(63.4 \%)$ & $17(81 \%)$ & 0.108 \\
\hline \multicolumn{5}{|l|}{ Actual occupational status } \\
\hline Employed-no (\%) & $113(50.0 \%)$ & $100(48.8 \%)$ & $13(61.9 \%)$ & \multirow[t]{3}{*}{0.335} \\
\hline Unemployed-no (\%) & $13(5.8 \%)$ & $13(6.3 \%)$ & $0(0 \%)$ & \\
\hline Retiree-no (\%) & $98(44.2 \%)$ & $92(44.9 \%)$ & $8(38.1 \%)$ & \\
\hline
\end{tabular}

*Incomplete data due to the impossibility to contact the non-responders

$B M I$ Body Mass Index, COPD Chronic Obstructive Pulmonary Disease, MELD Model for End stage Liver Disease, SAPS Simplified Acute Physiology Score, SOFA Sequential Organ Assessment Score, ICU Intensive Care Unit, ARDS Acute Respiratory Distress Syndrome

(severe vs moderate) or five adjunctive days of invasive mechanical ventilation can significantly worsen 90 days HRQoL of more than 0.015 . For clarification, decreases of this entity are associated to a decrease in a subjective five-category global assessment scale evaluating HRQoL change of one or more classes (e.g., from "much the same" to "slightly worse" or "much worse") [25]. 
Table 2 Health-related quality of life dimensions of the respondents compared with age- and sex-matched Italian and Finnish populations

\begin{tabular}{|c|c|c|c|c|c|c|}
\hline Health-related Quality of Life & Respondents $(n=205)$ & $\begin{array}{l}\text { General Ital- } \\
\text { ian population } \\
(n=205)\end{array}$ & $\begin{array}{l}\text { General Finn- } \\
\text { ish population } \\
(\mathrm{n}=4752)\end{array}$ & $\begin{array}{l}p \text { (respond- } \\
\text { ents vs IT) }\end{array}$ & $\begin{array}{l}p \text { (respond- } \\
\text { ents vs FIN) }\end{array}$ & $\begin{array}{l}p \\
\text { (IT vs FIN) }\end{array}$ \\
\hline Mobility & $0.829 \pm 0.262$ & $0.975 \pm 0.104$ & $0.932 \pm 0.140$ & $<0.001$ & $<0.001$ & $<0.001$ \\
\hline Vision & $0.933 \pm 0.143$ & $0.934 \pm 0.114$ & $0.958 \pm 0.116$ & 0.981 & 0.015 & 0.002 \\
\hline Hearing & $0.972 \pm 0.089$ & $0.968 \pm 0.115$ & $0.937 \pm 0.129$ & 0.695 & $<0.001$ & 0.001 \\
\hline Breathing & $0.730 \pm 0.238$ & $0.910 \pm 0.148$ & $0.935 \pm 0.146$ & $<0.001$ & $<0.001$ & 0.013 \\
\hline Sleeping & $0.837 \pm 0.226$ & $0.843 \pm 0.194$ & $0.846 \pm 0.171$ & 0.780 & 0.571 & 0.830 \\
\hline Eating & $0.945 \pm 0.176$ & $0.997 \pm 0.040$ & $0.997 \pm 0.037$ & $<0.001$ & $<0.001$ & 0.744 \\
\hline Speech & $0.959 \pm 0.139$ & $0.986 \pm 0.064$ & $0.982 \pm 0.079$ & 0.015 & 0.023 & 0.470 \\
\hline Excretion & $0.918 \pm 0.194$ & $0.911 \pm 0.173$ & $0.890 \pm 0.175$ & 0.674 & 0.037 & 0.140 \\
\hline Usual activities & $0.785 \pm 0.283$ & $0.958 \pm 0.130$ & $0.915 \pm 0.167$ & $<0.001$ & $<0.001$ & $<0.001$ \\
\hline Mental function & $0.875 \pm 0.201$ & $0.934 \pm 0.142$ & $0.885 \pm 0.180$ & 0.001 & 0.486 & $<0.001$ \\
\hline Discomfort and symptoms & $0.814 \pm 0.239$ & $0.936 \pm 0.141$ & $0.796 \pm 0.197$ & $<0.001$ & 0.271 & $<0.001$ \\
\hline Depression & $0.828 \pm 0.211$ & $0.893 \pm 0.169$ & $0.940 \pm 0.122$ & 0.001 & $<0.001$ & $<0.001$ \\
\hline Distress & $0.816 \pm 0.223$ & $0.811 \pm 0.205$ & $0.941 \pm 0.129$ & 0.816 & $<0.001$ & $<0.001$ \\
\hline Vitality & $0.779 \pm 0.230$ & $0.880 \pm 0.161$ & $0.821 \pm 0.145$ & $<0.001$ & $<0.001$ & 0.247 \\
\hline Sexual activity & $0.728 \pm 0.301$ & $0.866 \pm 0.215$ & $0.867 \pm 0.224$ & $<0.001$ & $<0.001$ & 0.691 \\
\hline $15 \mathrm{D}$ & $0.850 \pm 0.143$ & $0.929 \pm 0.809$ & $0.914 \pm 0.084$ & $<0.001$ & $<0.001$ & 0.030 \\
\hline
\end{tabular}

All the variables are expressed as mean \pm SD. $p$ values are referred to two-sided t-test

Fig. 2 15D profile of the COVID-19-related ARDS survivors compared with age- and sex-matched Italian and Finnish populations

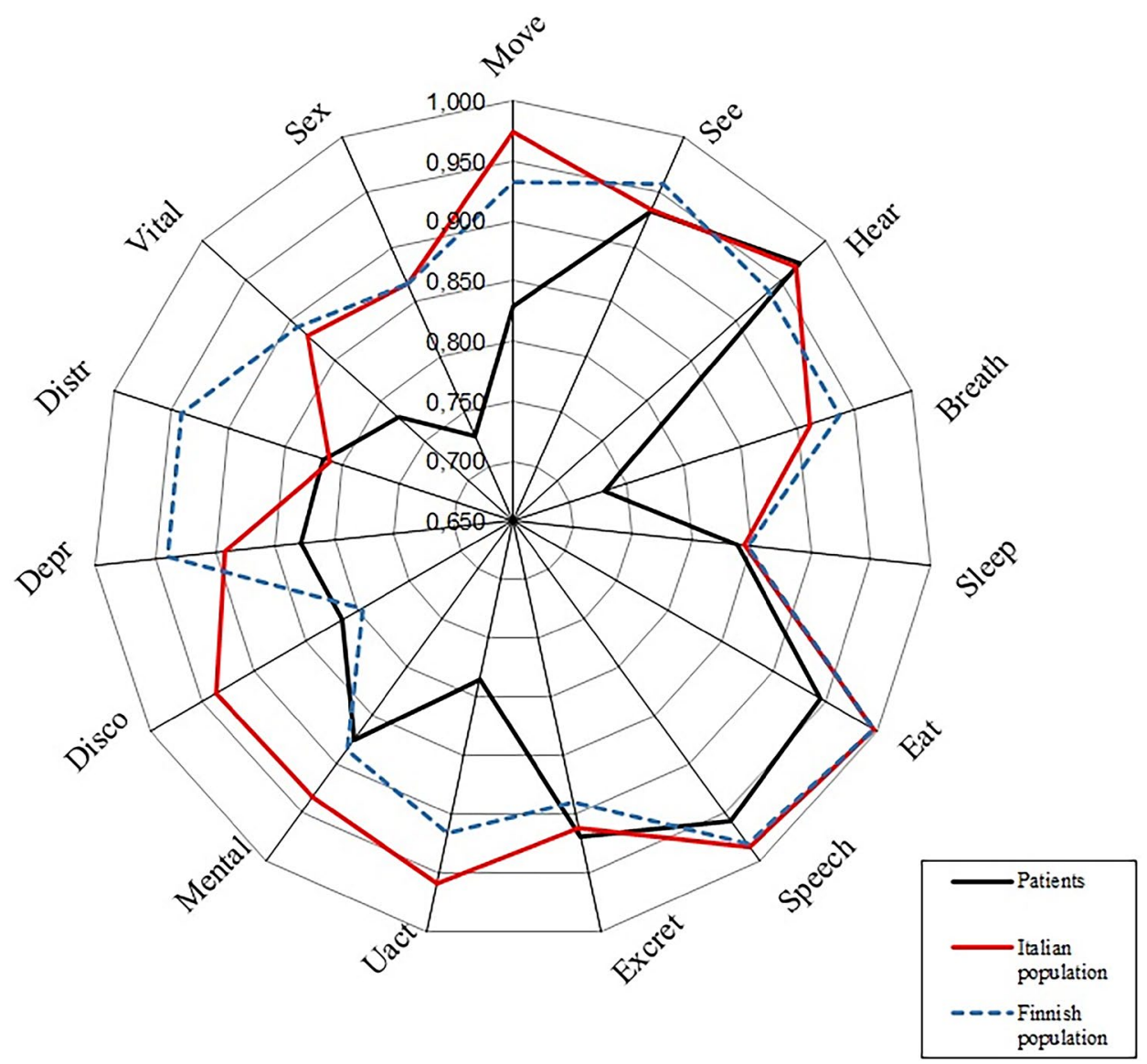


Table 3 Linear regression analysis

\begin{tabular}{|c|c|c|c|c|c|c|}
\hline \multirow[t]{2}{*}{ Variable $(N=205)$} & \multicolumn{3}{|c|}{ Univariate analysis } & \multicolumn{3}{|c|}{ Multivariate analysis } \\
\hline & $\beta$ & $95 \% \mathrm{CI}$ & $p$ & $\beta$ & $95 \% \mathrm{CI}$ & $p$ \\
\hline Gender (female) & -0.024 & $-0.069 ; 0.020$ & 0.278 & -0.043 & $-0.086 ;-0.001$ & 0.045 \\
\hline Age (years) & -0.002 & $-0.004 ; 0.000$ & 0.066 & -0.004 & $-0.006 ;-0.001$ & 0.003 \\
\hline BMI $\left(\mathrm{Kg} / \mathrm{m}^{2}\right)$ & -0.002 & $-0.006 ; 0.002$ & 0.410 & -0.001 & $-0.005 ; 0.003$ & 0.556 \\
\hline Number of comorbidities $(n)$ & -0.031 & $-0.052 ;-0.010$ & 0.004 & -0.023 & $-0.043 ;-0.002$ & 0.032 \\
\hline ARDS class $^{\mathrm{a}}$ (reference class: severe) & 0.030 & $-0.005 ; 0.065$ & 0.065 & 0.040 & $0.007 ; 0.073$ & 0.019 \\
\hline SAPS II score & -0.001 & $-0.003 ; 0.001$ & 0.206 & & & - \\
\hline SOFA score at ICU admission & -0.001 & $-0.010 ; 0.009$ & 0.908 & 0.008 & $-0.001 ; 0.017$ & 0.073 \\
\hline Intravenous corticosteroids (yes) & 0.014 & $-0.028 ; 0.057$ & 0.504 & 0.020 & $-0.020 ; 0.060$ & 0.330 \\
\hline Neuromuscular blocking agents continuous infusion (yes) & -0.002 & $-0.070 ; 0.066$ & 0.952 & & & - \\
\hline Prone positioning (yes) & 0.031 & $-0.010 ; 0.072$ & 0.133 & 0.036 & $-0.003 ; 0.076$ & 0.076 \\
\hline Vasoactive drugs (yes) & -0.052 & $-0.093 ;-0.013$ & 0.010 & -0.039 & $-0.079 ; 0.002$ & 0.060 \\
\hline Duration of invasive mechanical ventilation (days) & -0.003 & $-0.004 ;-0.001$ & 0.001 & -0.003 & $-0.004 ;-0.001$ & 0.001 \\
\hline Tracheostomy (yes) & -0.042 & $-0082 ;-0.002$ & 0.039 & -0.016 & $-0.058 ; 0.025$ & 0.436 \\
\hline ICU length of stay (days) & -0.002 & $-0.003 ;-0.001$ & 0.004 & & & - \\
\hline Renal replacement therapy (yes) & -0.047 & $-0.123 ; 0.029$ & 0.221 & & & - \\
\hline ICU stay complications-non-pulmonary (yes) & -0.022 & $-0.063 ; 0.018$ & 0.278 & & & - \\
\hline ICU stay-infectious pulmonary complications (yes) & -0.007 & $-0.048 ; 0.033$ & 0.720 & & & - \\
\hline Marital status-unmarried/non-cohabitee & -0.013 & $-0.059 ; 0.034$ & 0.597 & & & - \\
\hline Instruction degree-high school or higher & -0.004 & $-0.045 ; 0.037$ & 0.850 & & & - \\
\hline Occupational status-employed ${ }^{\mathrm{b}}$ & 0.146 & $0.065 ; 0.227$ & $<0.001$ & 0.105 & $0.027 ; 0.184$ & 0.009 \\
\hline Occupational status-retiree ${ }^{b}$ & 0.141 & $0.060 ; 0.223$ & 0.001 & 0.175 & $0.094 ; 0.257$ & $<0.001$ \\
\hline
\end{tabular}

Dependant variable: $15 \mathrm{D}$ score

${ }^{\text {a}}$ Per class increase, reference class: severe ARDS

${ }^{\mathrm{b}}$ Reference category for occupational status: unemployed. Multiple $\mathrm{R}^{2}$ for the model: 0.2503 , Adjusted $\mathrm{R}^{2}$ : 0.1999

BMI Body Mass Index, ARDS Acute Respiratory Distress Syndrome, SAPS Simplified Acute Physiology Score, SOFA Sequential Organ Assessment Score, ICU Intensive Care Unit

\section{Discussion}

In this study we used the $15 \mathrm{D}$ instrument to evaluate the HRQoL of COVID-19 critically ill survivors at 90 days after ICU discharge and compare it to two age- and sexmatched random populations. We found that (a) the HRQoL of COVID-19 critically ill survivors was significantly lower than the HRQoL of both contemporary general Italian population and Finnish pre-COVID population and (b) the most affected areas were mobility, breathing, eating, speech, usual activities, mental function, discomfort and symptoms, depression, vitality, and sexual activity, (c) moreover, age, female sex, comorbidities, ARDS class, duration of invasive mechanical ventilation, and occupational status were found to be significant determinants of 90 days HRQoL.

\section{D profile of the COVID-19 survivors}

A high percentage of ARDS survivors experience cognitive impairment after ICU recovery [26, 27], ranging from almost $100 \%$ at hospital discharge to $80 \%$ at 1 year [28,
30, 31]. Moreover, a high rate of persistent psychological and physical disability, such as muscle weakness [31] and incomplete lung function recovery [32], can be frequently found. It is debated if COVID-19-related ARDS could be defined as "classical" ARDS [33, 34] from a pathophysiological point of view. However, in most of the COVID-19 cases admitted to the ICU, the disease evolution seems to be similar to the severe forms of classical ARDS, requiring endotracheal intubation and being characterized by a prolonged and difficult weaning and consequently a prolonged ICU stay. Indeed, the HRQoL profile observed in our cohort of COVID-19 ARDS patients is very similar to those observed in non-COVID ARDS survivors [35-37]. This cohort of COVID-19 ARDS patients revealed significantly lower scores in the motion and usual activities dimensions of the 15D instrument compared to both the contemporary Italian and the Finnish pre-COVID-19 populations. The reduction in terms of physical components of the HRQoL instruments is common in both ICU survivors [21] and non-COVID ARDS survivors [35, 38]. 
Critical illness acquired weakness (ICUAW) [39], compressive neuropathies, and non-specific structural changes in muscle are the main causes of weakness and reduced exercise capacity in ARDS survivors [40]. Muscular wasting can be consequent to prolonged mechanical ventilation, exposure to sedatives, neuromuscular blocking agents, and corticosteroids, as well as malnutrition and hypercatabolic state [41, 42]. Recent reports in COVID-19 ARDS population highlighted an ICUAW incidence of $27 \%$ at ICU discharge [43], and this could have a central role in the significant deflection of the physical dimensions found using the 15D instrument.

The impairment in several pulmonary function tests has already been associated with worse scores in the physical components of HRQoL [44]. Indeed, we found a significant reduction of the breathing dimension in COVID-19 ARDS patients. Preliminary studies reported impaired pulmonary function tests in COVID-19 survivors, mostly in Carbon Monoxide Diffusing Capacity [34, 45]. Moreover, persistent weakness of the respiratory muscles and lung imaging abnormalities were reported mostly in the early post-hospital discharge phase [46] and our data on follow-up CT scans confirmed these results (see Supplement Table S1).

Tracheostomy is notoriously associated with swallowing and vocalization problems that need rehabilitation. Despite this variable was excluded from the final regression model during the stepwise selection, literature reports a severe reduction in long-term quality of life in tracheostomized general ICU patients [47]. The high prevalence of tracheostomies in the COVID-19 population could have contributed to the reduction on the eating and speech dimensions of the $15 \mathrm{D}$ instrument observed in our study population. Since tracheostomy is often a necessary procedure for the prolonged mechanical ventilation and the consequent difficult weaning process, optimal timing, and vocal rehabilitation can be taken into consideration in order to try to improve HRQoL $[48,49]$.

In non-COVID-19 ARDS, a high prevalence of longterm cognitive impairment and psychiatric disorders has been described: depression, anxiety disorders, and posttraumatic stress disorder (PTSD) [28, 36, 50]. Indeed, prolonged hypoxia, physical, and psychic stressors related to the ICU experience could favor acute brain dysfunction and impair the coping mechanisms in response to stress events. COVID-19 patients, compared to previous cohorts of ARDS patients, experienced a profound social isolation during all the time of the hospital stay, in most of the cases more than a month. Indeed, in COVID-19 wards, no access was allowed to relatives or visitors and, moreover, these latter were frequently quarantined at home. Moreover, the need to wear full personal protective equipment by the healthcare personnel invariably complicated the communication processes and could have probably contributed to the social isolation described above.
The components of mental function and depression of the 15D instrument in COVID-19 ARDS survivors were significantly lower with respect to their matched Italian controls as already described for non-COVID-19 ARDS survivors. In a previous study on a large sample of general ICU patients with respiratory failure or shock [27], at three months after ICU discharge, $40 \%$ of them had global cognition scores that were worse than those typically seen in patients with moderate traumatic brain injury, and this impairment lasted at 1 year after ICU discharge in $34 \%$ of them. The occurrence of delirium during ICU stay and its duration were positively correlated with lower cognition scores after ICU discharge [27]. Recent reports evidenced a very high prevalence (84.3\%) of delirium in the COVID-19 ICU population, that was also responsible for prolonged mechanical ventilation, another factor significantly associated to a reduced HRQoL in our population [51]. Therefore, this aspect needs attention during both ICU stay and after discharge for the development of rehabilitative programs.

Interestingly, the distress dimension values of COVID-19 survivors were not significantly different from Italian general population but it was significantly lower than in the pre-COVID Finnish general population, while the sleeping dimension was not significantly affected with respect to general Italian and Finnish populations. The COVID-19 pandemics produced high levels of anxiety in the overall population of the most affected areas [52] and a recent crosssectional study enrolling over 7000 self-selected Chinese volunteers reported a prevalence of general anxiety disorder, depressive symptoms and bad quality of sleep of, respectively, $35.1 \%, 20.1 \%$, and $18.2 \%$ [53].

Italy, together with China, was one of the most affected countries during the first wave of the COVID-19 pandemic and the expected increase in terms of anxiety disorder and sleep disturbances could probably have partially smoothed the differences between the post-critical COVID-19 population and the general post-COVID-19 Italian population in terms of distress and sleeping dimensions.

\section{Factors associated with reduced $\mathrm{HRQ} \mathrm{OL}$}

Our study underlines that, in COVID-19 patients, ARDS class, prolonged mechanical ventilation, older age [54], female sex and comorbidities are associated with worse scores in HRQoL as already reported in "classical" ARDS survivors [35-37]. Moreover, ARDS severity resulted independently associated to HRQoL with a notably high $\beta$ coefficient $(\beta=0.040$ per class increase from severe as reference category). Few studies evaluated the potential impact of initial ARDS severity on reported HRQoL and our results could have been influenced by both the relatively short follow-up time and the high homogeneity of the sample in terms of etiology, in fact, most of the other studies reporting 
HRQoL after ARDS had mixed etiology samples [37, 38, 55]. Female sex was also independently associated to worse HRQoL in the final multivariate model, this result is in contrast with the only other study evaluating this variable in non-COVID-19 respiratory failure [56], the relatively small sample of women in our series and the different reporting of symptoms between sexes could have had a role in determining this result. No other clinical variables investigated in the study, SAPS II score and SOFA score at ICU admission, resulted significantly associated with HRQoL, in line with available literature for non-COVID ARDS [35, 55].

In the COVID-19 ARDS cohort, the ability to return to work and the retiree status were significantly associated with better HRQoL with respect to the unemployed status. The ability to return to work is known to be positively associated with HRQoL and has been proposed as an outcome measure since it is considered a good operationalization for overcoming morbidity [57].

The marital status and degree of instruction were not significantly associated with HRQoL values and no other follow-up studies on ARDS described these aspects. However, these social variables usually play a significant role in determining the quality of life in other cross-sectional studies. It is possible that, at 90 days from ICU discharge, the entity of disability related to clinical factors outweighs these social aspects in determining HRQoL.

\section{Limitations}

Our study has several limitations. First, the 15D instrument was originally developed to be self-administered, even if telephonic administration is possible. For this study, we administered the questionnaire using a telephonic interview mainly because of 1) the distance of patients that were transiently admitted to the study ICUs from other provinces, 2) the limitations related to the postal transmission of potentially infected documents and 3) the difficulty of older age patients to deal with eventual email transmission of the questionnaires.

Self-reporting questionnaires based on checklists of endorsed symptoms or severity scores could influence both the prevalence of symptoms investigated and the domain severity scores [58]; however, this problem is common to all the other HRQoL instruments based on closed-ended questions.

Missing data for the 15D instrument were globally extremely low, with the exception of the sexual activity dimension that reached $13.4 \%$, this percentage may be culture-dependent or related to the telephone interview that could have induced more reluctance to reply to this sensitive question if compared to self-administration.

A comparison between COVID-19 ARDS and nonCOVID-19 ARDS would have been interesting; however, when this study was designed, it was not clear if COVID19 pneumonia could be considered and ARDS form [59, $60]$ and, moreover, the number of non-COVID forms during the pandemic dramatically fell; therefore, it would have been impossible to build an adequate control group. Indeed, the use of data from patients experiencing ARDS before COVID-19 pandemic would have been biased by the absence of COVID-related restrictions (such as lockdown and limitations of the visits from relatives to ICU admitted patients, independently from their COVID-19 status).

The control population was built on the basis of an age and sex match; however, comorbidities were not taken into account and this could be another limitation in the interpretation of our results.

Ninety days are a short follow-up for ARDS patients, but it could give early indication about the potential areas of intervention in these patients especially after hospital discharge.

Finally, most of the other studies about HRQoL in ARDS survivors used the SF-36 instrument thus leading to limited comparability of our results. However, the 15D instrument was chosen because it can simultaneously evaluate a wide range of dimensions. This can be an advantage in assessing a still not well categorized population. Moreover, the 15D instrument results demonstrated a good correlation with SF-36 and the majority of the other generic HRQoL measurement instruments [61].

\section{Conclusions}

COVID-19-related ARDS survivors at 90 days after ICU discharge present a significant reduction in both physical and psychological dimensions of HRQoL measured with the $15 \mathrm{D}$ instrument. The degree of reduction in HRQoL is mainly influenced by baseline clinical conditions, length of mechanical ventilation, and social factors. Due to the complexity of these patients, a multidisciplinary approach, as well as social support, can be fundamental in granting an adequate recovery after COVID-19 critical illness.

Supplementary Information The online version contains supplementary material available at https://doi.org/10.1007/s11136-021-02865-7.

Acknowledgements ICU-RER COVID-19 Collaboration - List of collaborators (to be indexed and searchable into PubMed): Maggiore Hospital Carlo Alberto Pizzardi, Bologna, IT: Marco Tartaglione, Valentina Chiarini, Virginia Buldini, Carlo Coniglio, Federico Moro, Clara Barbalace, Mario Citino. Bellaria Hospital, Bologna, IT: Nicola Cilloni, Lorenzo Giuntoli, Angela Bellocchio, Emanuele Matteo. Sant'OrsolaMalpighi University Hospital, Bologna, IT: Giacinto Pizzilli, Antonio Siniscalchi, Chiara Tartivita, Francesco Matteo. Imola Hospital, Bologna, IT: Annalisa Marchio, Igor Bacchilega. Infermi Hospital, Rimini, IT: Laura Bernabé, Sonia Guarino, Elena Mosconi.M.Bufalini Hospital, Cesena, IT: Luca Bissoni, Lorenzo Viola, Emiliano Gamberini. 
Santa Maria Annunziata Hospital, Firenze, IT: Tommaso Meconi, Vittorio Pavoni. SS. Trinità Hospital, ASL Novara, IT: Aline Pagni, Patrizia Pompa Cleta, Marco Cavagnino. Bentivoglio Hospital, Bentivoglio, IT: Anna Malfatto, Angelina Adduci, Silvia Pareschi. University Hospital of Modena, Modena, IT: Gabriele Melegari, Jessica Maccieri, Elisa Marinangeli. Azienda Ospedaliera SS. Antonio e Biagio e Cesare Arrigo, Alessandria, IT: Fabrizio Racca. University of Ferrara, Azienda Ospedaliero-Universitaria S. Anna, Cona, Ferrara, IT: Marco Verri, Giulia Falò, Elisabetta Marangoni. Villa Erbosa Hospital, San Donato Group, Bologna, IT: Francesco Boni. Santa Maria delle Croci Hospital, Ravenna, IT: Giulia Felloni, Federico Domenico Baccarini. Morgagni-Pierantoni Hospital, Forlì, IT: Marina Terzitta, Stefano Maitan. Azienda USL Toscana Centro, Prato, IT: Maddalena Parise, Bernardo Bugiani, Francesca Masoni. Radiology Collaborators (to be indexed and searchable into PubMed): Maggiore Hospital Carlo Alberto Pizzardi, Bologna, IT: Michele Imbriani, Paolo Orlandi. Bellaria Hospital, Bologna, IT: Giorgia Dalpiaz. Sant'Orsola-Malpighi University Hospital, Bologna, IT: Rita Golfieri, Federica Ciccarese. Imola Hospital, Bologna, IT: Antonio Poerio. Infermi Hospital, Rimini, IT: Francesco Muratore, Fabio Ferrari. M.Bufalini Hospital, Cesena, IT: Martina Mughetti. SS. Trinità Hospital, ASL Novara, IT: Loredana Franchini, Ersenad Neziri. Bentivoglio Hospital, Bentivoglio, IT: Marco Miceli. Santa Maria delle Croci Hospital, Ravenna, IT: Maria Teresa Minguzzi, Lorenzo Mellini. Morgagni-Pierantoni Hospital, Forlì, IT: Sara Piciucchi.

Authors contributions LG, TT, SS, GZ, CC, EG, and CAM concepted and designed the work. VA, FB, EB, AC, IC, IC, FC, FD, MF, GG, CL, MCL, ML, AM, GN, IO, RP, AP, VMR, ER, and ST acquired and interpreted the data. DA and HS performed the statistical analysis. LG, CAM, IO, and DC drafted the article. HS, SS, GS, and CAV substantively revised the article. The ICU-RER COVID-19 collaboration was involved in data collection (see acknowledgments). All the Authors have approved the submitted version and have agreed both to be personally accountable for the author's own contributions and to ensure that questions related to the accuracy or integrity of any part of the work, even ones in which the author was not personally involved.

Funding None declared.

Data availability The datasets related to the Italian population used and/or analyzed during the current study are available at https://doi. org/10.17632/5hxnf9s7rk.1.For the Finnish population, please refer to Harri Sintonen (harri.sintonen@helsinki.fi).

\section{Declarations}

Conflict of interest Harri Sintonen is the developer of the 15D and obtains royalties from its electronic versions. The other Authors have nothing to disclose.

Ethical approval The study was approved by the Institutional Review Board (IRB) of the study coordinator centre (Maggiore Hospital, Bologna, Italy, approval number: 273/2020/OSS/AUSLBO) and by each institutional review committee of the participating hospitals.

Consent to participate Informed consent was waived for unconscious patients, while it was acquired for conscious patients or after liberation from mechanical ventilation or at the time of follow-up. The researchers analyzed anonymized individual data.

Consent for publication Not applicable.

\section{References}

1. WHO. (2020). WHO announces COVID-19 outbreak a pandemic.

2. Aziz, Shadman, Arabi, Yaseen M., Alhazzani, Waleed, Evans, Laura, Citerio, Giuseppe, Fischkoff, Katherine, Salluh, Jorge, Meyfroidt, Geert, Alshamsi, Fayez, Oczkowski, Simon, Azoulay, Elie, Price, Amy, Burry, Lisa, Dzierba, Amy, Benintende, Andrew, Morgan, Jill, Grasselli, Giacomo, Rhodes, Andrew, Møller, Morten H., ... Christian, Michael D. (2020). Managing ICU surge during the COVID-19 crisis: rapid guidelines. Intensive Care Medicine, 46(7), 1303-1325. https://doi.org/10.1007/ s00134-020-06092-5

3. Grasselli, G., Pesenti, A., \& Cecconi, M. (2020). Critical Care Utilization for the COVID-19 Outbreak in Lombardy, Italy. JAMA. https://doi.org/10.1001/jama.2020.4031

4. Melegari, G., Giuliani, E., Maini, G., Barbieri, L., Baffoni, P., Bertellini, E., \& Barbieri, A. (2020). Novel coronavirus (2019nCov): do you have enough intensive care units? Medicina Intensiva, 44(9), 583-585. https://doi.org/10.1016/j.medin.2020.04.007

5. Grasselli, G., Zangrillo, A., Zanella, A., Antonelli, M., Cabrini, L., Castelli, A., \& Pesenti, A. (2020). Baseline Characteristics and Outcomes of 1591 Patients Infected with SARS-CoV-2 Admitted to ICUs of the Lombardy Region, Italy. JAMA - Journal of the American Medical Association, 323(16), 1574-1581. https://doi. org/10.1001/jama.2020.5394

6. Richardson, S., Hirsch, J. S., Narasimhan, M., Crawford, J. M., McGinn, T., Davidson, K. W., \& Zanos, T. P. (2020). Presenting Characteristics, Comorbidities, and Outcomes among 5700 Patients Hospitalized with COVID-19 in the New York City Area. JAMA - Journal of the American Medical Association, 323(20), 2052-2059. https://doi.org/10.1001/jama.2020.6775

7. Auld, S. C., Caridi-Scheible, M., Blum, J. M., Robichaux, C., Kraft, C., Jacob, J. T., \& Murphy, D. J. (2020). ICU and Ventilator Mortality Among Critically Ill Adults With Coronavirus Disease 2019. Critical Care Medicine, Publish Ah. https://doi. org/10.1097/ccm.0000000000004457

8. Grasselli, G., Greco, M., Zanella, A., Albano, G., Antonelli, M., Bellani, G., \& Cecconi, M. (2020). Risk Factors Associated with Mortality among Patients with COVID-19 in Intensive Care Units in Lombardy, Italy. JAMA Internal Medicine. https://doi.org/10. 1001/jamainternmed.2020.3539

9. Quah, P., Li, A., Phua, J., \& Phua, J. (2020). Mortality rates of patients with COVID-19 in the intensive care unit: A systematic review of the emerging literature. Critical Care, 24(1), 1-4. https://doi.org/10.1186/s13054-020-03006-1

10. Lopez, M., Bell, K., Annaswamy, T., Juengst, S., \& Ifejika, N. (2020). COVID-19 Guide for the Rehabilitation Clinician: A Review of Nonpulmonary Manifestations and Complications. American journal of physical medicine \& rehabilitation, 99(8), 669-673. https://doi.org/10.1097/PHM.0000000000001479

11. Jaffri, A., \& Jaffri, U. A. (2020). Post-Intensive care syndrome and COVID-19: crisis after a crisis? Heart and Lung. https://doi.org/ 10.1016/j.hrtlng.2020.06.006

12. Colbenson, G. A., Johnson, A., \& Wilson, M. E. (2019). Postintensive care syndrome: Impact, prevention, and management. Breathe, 15(2), 98-101. https://doi.org/10.1183/20734735. 0013-2019

13. Stollings, J. L., \& Caylor, M. M. (2015). Postintensive care syndrome and the role of a follow-up clinic. American Journal of Health-System Pharmacy, 72(15), 1315-1323. https://doi.org/10. 2146/ajhp140533

14. Jackson, J. C., Pandharipande, P. P., Girard, T. D., Brummel, N. E., Thompson, J. L., Hughes, C. G., \& Ely, E. W. (2014). Depression, post-traumatic stress disorder, and functional disability in survivors of critical illness in the BRAIN-ICU study: 
A longitudinal cohort study. The Lancet Respiratory Medicine, 2(5), 369-379. https://doi.org/10.1016/S2213-2600(14)70051-7

15. Sasannejad, C., Ely, E. W., \& Lahiri, S. (2019). Long-term cognitive impairment after acute respiratory distress syndrome: A review of clinical impact and pathophysiological mechanisms. Critical Care, 23(1), 1-12. https://doi.org/10.1186/ s13054-019-2626-z

16. Gayat, E., Cariou, A., Deye, N., Vieillard-Baron, A., Jaber, S., Damoisel, C., \& Mebazaa, A. (2018). Determinants of longterm outcome in ICU survivors: Results from the FROG-ICU study. Critical Care, 22(1), 1-10. https://doi.org/10.1186/ s13054-017-1922-8

17. Bein, T., Weber-Carstens, S., \& Apfelbacher, C. (2018). Longterm outcome after the acute respiratory distress syndrome: Different from general critical illness? Current Opinion in Critical Care, 24(1), 35-40. https://doi.org/10.1097/MCC.0000000000 000476

18. Chiumello, D., Coppola, S., Froio, S., \& Gotti, M. (2016). What's next after ARDS: Long-term outcomes. Respiratory Care, 61(5), 689-699. https://doi.org/10.4187/respcare.04644

19. Brummel, N. E., Jackson, J. C., Pandharipande, P. P., Thompson, J. L., Shintani, A. K., Dittus, R. S., \& Girard, T. D. (2014). Delirium in the ICU and subsequent long-term disability among survivors of mechanical ventilation. Critical Care Medicine, 42(2), 369-377. https://doi.org/10.1097/CCM.0b013e3182 a645bd

20. Stam, H. J., Stucki, G., \& Bickenbach, J. (2020). Covid-19 and post intensive care syndrome: A call for action. Journal of Rehabilitation Medicine, 52(4), 19-22. https://doi.org/10.2340/ 16501977-2677

21. Langerud, A. K., Rustøen, T., Småstuen, M. C., Kongsgaard, U., $\&$ Stubhaug, A. (2018). Health-related quality of life in intensive care survivors: Associations with social support, comorbidity, and pain interference. PLOS ONE, 13(6), 1-13. https://doi. org/10.1371/journal.pone.0199656

22. Koskinen, S., Lundqvist, A., Welfare, N. R.-N. I. for H. and, \& 2012, U. (n.d.). Health, functional capacity and welfare in Finland in 2011. Retrieved from https://www.julkari.fi/bitstream/ handle/10024/90832/Rap068_2012_netti.pdf?sequence $=1 \&$ is Allowed $=\mathrm{y}$

23. Ferguson, N. D., Fan, E., Camporota, L., Antonelli, M., Anzueto, A., Beale, R., \& Marco Ranieri, V. (2012). The Berlin definition of ARDS: An expanded rationale, justification, and supplementary material. Intensive Care Medicine, 38(10), 1573-1582. https://doi. org/10.1007/s00134-012-2682-1

24. Sintonen, H. (2001). The $15 \mathrm{D}$ instrument of health-related quality of life: Properties and applications. Annals of Medicine, 33(5), 328-336. https://doi.org/10.3109/07853890109002086

25. Alanne, S., Roine, R. P., Räsänen, P., Vainiola, T., \& Sintonen, H. (2015). Estimating the minimum important change in the $15 \mathrm{D}$ scores. Quality of Life Research, 24(3), 599-606. https://doi.org/ 10.1007/s11136-014-0787-4

26. de Oliveira, R. P., Teixeira, C., \& Rosa, R. G. (2019). Acute respiratory distress syndrome: How do patients fare after the intensive care unit? Revista Brasileira de Terapia Intensiva, 31(4), 555-560. https://doi.org/10.5935/0103-507X.20190074

27. Pandharipande, P. P., Girard, T. D., Jackson, J. C., Morandi, A., Thompson, J. L., Pun, B. T., \& Ely, E. W. (2013). Long-term cognitive impairment after critical illness. New England Journal of Medicine, 369(14), 1306-1316. https://doi.org/10.1056/NEJMo a1301372

28. Herridge, M. S., Moss, M., Hough, C. L., Hopkins, R. O., Rice, T. W., Bienvenu, O. J., \& Azoulay, E. (2016). Recovery and outcomes after the acute respiratory distress syndrome (ARDS) in patients and their family caregivers. Intensive Care Medicine, 42(5), 725-738. https://doi.org/10.1007/s00134-016-4321-8
29. Tibshirani, R., Johnstone, I., Hastie, T., \& Efron, B. (2004). Least angle regression. The Annals of Statistics, 32(2), 407-499. https:// doi.org/10.1214/009053604000000067

30. Matte-martyn, A., Diaz-granados, N., Al-saidi, F., Cooper, A. B., \& Trials, C. (2003). One-Year Outcomes in Survivors of the Acute Respiratory Distress Syndrome Margaret. New England Journal of Medicine, 348, 683-693

31. Cohen-Mansfield, Jiska, Dakheel-Ali, Maha, Marx, Marcia S., Thein, Khin, Natalie, G., \& Regier, P. (2017). Muscle Weakness and 5-Year Survival in Acute Respiratory Distress Syndrome Survivors. Physiology \& behavior, 176(1), 139-148. https://doi.org/ 10.1016/j.physbeh.2017.03.040

32. Raymond, E., Pisano, E., Gatsonis, C., Boineau, R., Domanski, M., Troutman, C., \& Luceri, R. M. (2011). Functional Disability 5 Years after Acute Respiratory Distress Syndrome Margaret. Heart Failure, 364(6), 225-237

33. Gattinoni, L., Coppola, S., Cressoni, M., Busana, M., Rossi, S., \& Chiumello, D. (2020). COVID-19 does not lead to a "typical" acute respiratory distress syndrome. American Journal of Respiratory and Critical Care Medicine. https://doi.org/10.1164/rccm. 202003-0817LE

34. Li, X., \& Ma, X. (2020). Acute respiratory failure in COVID-19: Is it "typical" ARDS? Critical Care, 24(1), 1-5. https://doi.org/ 10.1186/s13054-020-02911-9

35. Brown, S. M., Wilson, E., Presson, A. P., Zhang, C., Dinglas, V. D., Greene, T., \& Needham, D. M. (2017). Predictors of 6-month health utility outcomes in survivors of acute respiratory distress syndrome. Thorax, 72(4), 311-317. https://doi.org/10.1136/thora xjnl-2016-208560

36. Hopkins, R. O., Weaver, L. K., Chan, K. J., \& Orme, J. F. (2004). Quality of life, emotional, and cognitive function following acute respiratory distress syndrome. Journal of the International Neuropsychological Society, 10(7), 1005-1017. https://doi.org/10. 1017/S135561770410711X

37. Schelling, G., Stoll, C., Vogelmeier, C., Hummel, T., Behr, J., Kapfhammer, H. P., \& Briegel, J. (2000). Pulmonary function and health-related quality of life in a sample of long-term survivors of the acute respiratory distress syndrome. Intensive Care Medicine, 26(9), 1304-1311. https://doi.org/10.1007/s001340051342

38. Masclans, J. R., Roca, O., Muñoz, X., Pallisa, E., Torres, F., Rello, J., \& Morell, F. (2011). Quality of life, pulmonary function, and tomographic scan abnormalities after ARDS. Chest, 139(6), 1340-1346. https://doi.org/10.1378/chest.10-2438

39. Hermans, G., \& Van den Berghe, G. (2015). Clinical review: Intensive care unit acquired weakness. Critical Care, 19(1), 1-9. https://doi.org/10.1186/s13054-015-0993-7

40. Angel, M. J., Bril, V., Shannon, P., \& Herridge, M. S. (2007). Neuromuscular function in survivors of the acute respiratory distress syndrome. Canadian Journal of Neurological Sciences, 34(4), 427-432. https://doi.org/10.1017/S0317167100007307

41. De Jonghe, B., Sharshar, T., Lefaucheur, J. P., Authier, F. J., Durand-Zaleski, I., Boussarsar, M., \& Bastuji-Garin, S. (2002). Paresis acquired in the intensive care unit: A prospective multicenter study. Journal of the American Medical Association, 288(22), 2859-2867. https://doi.org/10.1001/jama.288.22.2859

42. Llano-Diez, M., Renaud, G., Andersson, M., Marrero, H. G., Cacciani, N., Engquist, H., \& Larsson, L. (2012). Mechanisms underlying ICU muscle wasting and effects of passive mechanical loading. Critical care (London, England), 16(5), R209. https://doi. org/10.1186/cc11841

43. Van Aerde, N., Van den Berghe, G., Wilmer, A., Gosselink, R., Hermans, G., Meersseman, P., \& Wouters, P. J. (2020). Intensive care unit acquired muscle weakness in COVID-19 patients. Intensive Care Medicine. https://doi.org/10.1007/s00134-020-06244-7

44. Li, T. S., Gomersall, C. D., Joynt, G. M., Chan, D. P. S., Leung, P., $\&$ Hui, D. S. C. (2006). Long-term outcome of acute respiratory 
distress syndrome caused by severe acute respiratory syndrome (SARS): an observational study. Critical care and resuscitation : journal of the Australasian Academy of Critical Care Medicine, 8(4), 302-308

45. Zhao, Y. Miao., Shang, Y. Min., Song, W. Bin., Li, Q. Quan., Xie, H., Xu, QFu., \& Xu, A. Guo. (2020). Follow-up study of the pulmonary function and related physiological characteristics of COVID-19 survivors three months after recovery. EClinicalMedicine. https://doi.org/10.1016/j.eclinm.2020.100463

46. Mo, X., Jian, W., Su, Z., Chen, M., Peng, H., Peng, P., \& Li, S. (2020). Abnormal pulmonary function in COVID-19 patients at time of hospital discharge. European Respiratory Journal, 55(6), 2-5. https://doi.org/10.1183/13993003.01217-2020

47. Vargas, Maria, Sutherasan, Yuda, Brunetti, Iole, Micalizzi, Camilla, Insorsi, Angelo, Ball, Lorenzo, Folentino, Marta, Sileo, Rosanna, De Lucia, Arduino, Cerana, Manuela, Accattatis, Alessandro, De Lisi, Domenico, Gratarola, Angelo, Mora, Francesco, Peretti, Giorgio, Servillo, Giuseppe, \& Pelosi, Paolo. (2018). Mortality and long-term quality of life after percutaneous tracheotomy in Intensive Care Unit: A prospective observational study. Minerva Anestesiologica, 84(9), 1024-1031. https://doi.org/10. 23736/S0375-9393.18.12133-X

48. McGrath, Brendan A., Brenner, Michael J., Warrillow, Stephen J., Pandian, Vinciya, Arora, Asit, Cameron, Tanis S., Añon, José Manuel., Martínez, Gonzalo Hernández, Truog, Robert D., Block, Susan D., Lui, Grace C Y., McDonald, Christine, Rassekh, Christopher H., Atkins, Joshua, Qiang, Li., Vergez, Sébastien., Dulguerov, Pavel, Zenk, Johannes, Antonelli, Massimo, ... FellerKopman, David J. (2020). Tracheostomy in the COVID-19 era: global and multidisciplinary guidance. The Lancet Respiratory Medicine, 8(7), 717-725. https://doi.org/10.1016/S2213-2600(20) 30230-7

49. Mattei, A., Amy de la Bretèque, B., Crestani, S., Crevier-Buchman, L., Galant, C., Hans, S., \& Giovanni, A. (2020). Guidelines of clinical practice for the management of swallowing disorders and recent dysphonia in the context of the COVID-19 pandemic. European Annals of Otorhinolaryngology, Head and Neck Diseases, 137(3), 173-175. https://doi.org/10.1016/j.anorl.2020.04. 011

50. Mikkelsen, M. E., Christie, J. D., Lanken, P. N., Biester, R. C., Thompson, B. T., Bellamy, S. L., \& Angus, D. C. (2012). The adult respiratory distress syndrome cognitive outcomes study: Long-term neuropsychological function in survivors of acute lung injury. American Journal of Respiratory and Critical Care Medicine, 185(12), 1307-1315. https://doi.org/10.1164/rccm. 201111-2025OC

51. Helms, J., Kremer, S., Merdji, H., Schenck, M., Severac, F., ClereJehl, R., \& Meziani, F. (2020). Delirium and encephalopathy in severe COVID-19: A cohort analysis of ICU patients. Critical Care, 24(1), 1-11. https://doi.org/10.1186/s13054-020-03200-1
52. Zhao, H., He, X., Fan, G., Li, L., Huang, Q., Qiu, Q., \& Xu, H. (2020). COVID-19 infection outbreak increases anxiety level of general public in China: involved mechanisms and influencing factors. Journal of Affective Disorders, 276(February), 446-452. https://doi.org/10.1016/j.jad.2020.07.085

53. Huang, Y., \& Zhao, N. (2020). Generalized anxiety disorder, depressive symptoms and sleep quality during COVID-19 outbreak in China: A web-based cross-sectional survey. Psychiatry Research. https://doi.org/10.1016/j.psychres.2020.112954

54. Herridge, M. S., Tansey, C. M., Matté, A., Tomlinson, G., DiazGranados, N., Cooper, A., \& Cheung, A. M. (2011). Functional Disability 5 Years after Acute Respiratory Distress Syndrome. $N$ Engl J Med. https://doi.org/10.1056/NEJMoa1011802

55. Angus, D. C., Musthafa, A. A., Clermont, G., Griffin, M. F., Linde-Zwirble, W. T., Dremsizov, T. T., \& Pinsky, M. R. (2001). Quality-adjusted survival in the first year after the acute respiratory distress syndrome. American Journal of Respiratory and Critical Care Medicine, 163(6), 1389-1394. https://doi.org/10. 1164/ajrccm.163.6.2005123

56. Briegel, I., Dolch, M., Irlbeck, M., Hauer, D., Kaufmann, I., \& Schelling, G. (2013). Ergebnisqualität der Therapie des akuten Lungenversagens: Veränderungen über einen Zeitraum von 2 Jahrzehnten. Der Anaesthesist, 62(4), 261-270. https://doi.org/10. 1007/s00101-013-2156-Z

57. Dodoo-Schittko, F., Brandstetter, S., Blecha, S., ThomannHackner, K., Brandl, M., Knüttel, H., \& Apfelbacher, C. (2017). Determinants of quality of life and return to work following acute respiratory distress syndrome - A systematic review. Deutsches Arzteblatt International, 114(7), 103-109. https://doi.org/10.3238/ arztebl.2017.0103

58. Edmed, S. L., Sullivan, K. A., Allan, A. C., \& Smith, S. S. (2015). Assessment method influences the severity and type of symptoms reported after self-reported mild traumatic brain injury. Journal of Clinical and Experimental Neuropsychology, 37(6), 641-652. https://doi.org/10.1080/13803395.2015.1038984

59. Gattinoni, L., Chiumello, D., Caironi, P., Busana, M., Romitti, F., Brazzi, L., \& Camporota, L. (2020). COVID-19 pneumonia: different respiratory treatments for different phenotypes? Intensive Care Medicine. https://doi.org/10.1007/s00134-020-06033-2

60. Gattinoni, L., Chiumello, D., \& Rossi, S. (2020). COVID-19 pneumonia: ARDS or not? Critical Care. BioMed Central Ltd. https:// doi.org/10.1186/s13054-020-02880-Z

61. Hawthorne, G., Richardson, J., \& Day, N. A. (2001). A comparison of the Assessment of Quality of Life (AQoL) with four other generic utility instruments. Annals of Medicine, 33, 358-370. https://doi.org/10.3109/07853890109002090

Publisher's Note Springer Nature remains neutral with regard to jurisdictional claims in published maps and institutional affiliations.

\title{
Authors and Affiliations
}

\author{
Lorenzo Gamberini ${ }^{1}$ - Carlo Alberto Mazzoli ${ }^{1}$. Harri Sintonen ${ }^{2}$. Davide Colombo ${ }^{3,4}$. Gaetano Scaramuzzo ${ }^{5}$. \\ Davide Allegri ${ }^{6}$. Tommaso Tonetti $^{7}$. Gianluca Zani ${ }^{8}$. Chiara Capozzi ${ }^{9} \cdot$ Emanuela Giampalma $^{10}$. Vanni Agnoletti ${ }^{11}$. \\ Filippo Becherucci ${ }^{12}$. Elisabetta Bertellini ${ }^{13,21}$. Andrea Castelli ${ }^{9} \cdot$ lacopo Cappellini ${ }^{12} \cdot$ Irene Cavalli ${ }^{7}$. \\ Federico Crimaldi ${ }^{13,21}$. Federica Damiani ${ }^{14}$. Maurizio Fusari ${ }^{8}$. Giovanni Gordini ${ }^{1}$. Cristiana Laici ${ }^{15}$. \\ Maria Concetta Lanza ${ }^{16} \cdot$ Mirco Leo $^{17}$. Andrea Marudi ${ }^{13,21}$. Giuseppe Nardi ${ }^{18}$. Irene Ottaviani ${ }^{5} \cdot$ Raffaella Papa $^{19}$. \\ Antonella Potalivo ${ }^{18}$. Vito Marco Ranieri ${ }^{7}$. Emanuele Russo ${ }^{11}$. Stefania Taddei ${ }^{20}$. Carlo Alberto Volta ${ }^{5}$. \\ Savino Spadaro ${ }^{5}$ - the ICU-RER COVID-19 Collaboration
}


1 Department of Anaesthesia, Intensive Care and Prehospital Emergency, Ospedale Maggiore Carlo Alberto Pizzardi, Bologna, Italy

2 Department of Public Health, University of Helsinki, Helsinki, Finland

3 Anaesthesia and Intensive Care Department, SS. Trinità Hospital, ASL Novara, Italy

4 Traslational Medicine Department, Eastern Piedmont University, Vercelli, Italy

5 Department of Morphology, Surgery and Experimental Medicine, Section of Anaesthesia and Intensive Care, University of Ferrara, Azienda Ospedaliero-Universitaria S. Anna, Via Aldo Moro, 8, 44121 Cona, Ferrara, Italy

6 Department of Clinical Governance and Quality, Bologna Local Healthcare Authority, Bologna, Italy

7 Alma Mater Studiorum, Dipartimento Di Scienze Mediche E Chirurgiche, Anesthesia and Intensive Care Medicine, Policlinico Di Sant'Orsola, Università Di Bologna, Bologna, Italy

8 Department of Anesthesia and Intensive Care, Santa Maria Delle Croci Hospital, Ravenna, Italy

9 Cardio-Anesthesiology Unit, Cardio-Thoracic-Vascular Department, S.Orsola Hospital, University of Bologna, Bologna, Italy

10 Radiology Department, M.Bufalini Hospital, Cesena, Italy

11 Anaesthesia and Intensive Care Unit, M.Bufalini Hospital, Cesena, Italy
12 Department of Critical Care Section of Anesthesiology and Intensive Care, Azienda USL Toscana Centro, Prato, Italy

13 Department of Anaesthesiology, University Hospital of Modena, Via del Pozzo 71, 41100 Modena, Italy

14 Department of Anaesthesia, Intensive Care and Pain Therapy, Imola Hospital, Imola, Italy

15 Division of Anesthesiology, Hospital S. Orsola Malpighi, Alma Mater Studiorum University of Bologna, Bologna, Italy

16 Department of Anesthesia and Intensive Care, G.B. Morgagni-Pierantoni Hospital, Forlì, Italy

17 Department of Anaesthesia and Intensive Care, Azienda Ospedaliera SS. Antonio E Biagio E Cesare Arrigo, Alessandria, Italy

18 Department of Anaesthesia and Intensive Care, Infermi Hospital, Rimini, Italy

19 Anaesthesia and Intensive Care Unit, Santa Maria Annunziata Hospital, Firenze, Italy

20 Anaesthesia and Intensive Care Unit, Bentivoglio Hospital, Bentivoglio, Italy

21 Anaesthesia and Intensive Care Residency ProgramTraslational Medicine Dept., Eastern Piedmont University, Vercelli, Italy 